\title{
Photoreceptor Disc Enclosure Is Tightly Controlled by Peripherin-2 Oligomerization
}

\author{
${ }^{\circledR}$ Tylor R. Lewis, ${ }^{1}$ Mustafa S. Makia, ${ }^{2}$ Carson M. Castillo, ${ }^{1}{ }^{\circledR}$ Muayyad R. Al-Ubaidi, ${ }^{2,3}{ }^{\circledR}$ Muna I. Naash, ${ }^{2,3}$ and \\ (1) Vadim Y. Arshavsky, \\ ${ }^{1}$ Department of Ophthalmology, Duke University Medical Center, Durham, North Carolina 27710, ${ }^{2}$ Department of Biomedical Engineering, \\ University of Houston, Houston, Texas $77204,{ }^{3}$ College of Optometry, University of Houston, Houston, Texas 77204, and ${ }^{4}$ Department of \\ Pharmacology and Cancer Biology, Duke University Medical Center, Durham, North Carolina 27710
}

Mutations in the PRPH2 gene encoding the photoreceptor-specific protein PRPH2 (also known as peripherin-2 or rds) cause a broad range of autosomal dominant retinal diseases. Most of these mutations affect the structure of the light-sensitive photoreceptor outer segment, which is composed of a stack of flattened "disc" membranes surrounded by the plasma membrane. The outer segment is renewed on a daily basis in a process whereby new discs are added at the outer segment base and old discs are shed at the outer segment tip. New discs are formed as serial membrane evaginations, which eventually enclose through a complex process of membrane remodeling (completely in rods and partially in cones). As disc enclosure proceeds, PRPH2 localizes to the rims of enclosed discs where it forms oligomers which fortify the highly curved membrane structure of these rims. In this study, we analyzed the outer segment phenotypes of mice of both sexes bearing a single copy of either the C150S or the Y141C PRPH2 mutation known to prevent or increase the degree of PRPH2 oligomerization, respectively. Strikingly, both mutations increased the number of newly forming, not-yet-enclosed discs, indicating that the precision of disc enclosure is regulated by PRPH2 oligomerization. Without tightly controlled enclosure, discs occasionally over-elongate and form large membranous "whorls" instead of disc stacks. These data show that the defects in outer segment structure arising from abnormal PRPH2 oligomerization are manifested at the stage of disc enclosure.

Key words: cilium; outer segment; peripherin; photoreceptor; photoreceptor disc; retina

\section{Significance Statement}

The light-sensitive photoreceptor outer segment contains a stack of flattened "disc" membranes that are surrounded, or "enclosed," by the outer segment membrane. Disc enclosure is an adaptation increasing photoreceptor light sensitivity by facilitating the diffusion of the second messenger along the outer segment axes. However, the molecular mechanisms by which photoreceptor discs enclose within the outer segment membrane remain poorly understood. We now demonstrate that oligomers of the photoreceptor-specific protein peripherin-2, or PRPH2, play an active role in this process. We further propose that defects in disc enclosure because of abnormal PRPH2 oligomerization result in major structural abnormalities of the outer segment, ultimately leading to loss of visual function and cell degeneration in PRPH2 mutant models and human patients.

Received Jan. 8, 2021; revised Feb. 15, 2021; accepted Mar. 5, 2021.

Author contributions: T.R.L., M.R.A.-U., M.I.N., and V.Y.A. designed research; T.R.L., M.S.M., and C.M.C. performed research; T.R.L., M.S.M., C.M.C., M.R.A.-U., M.I.N., and V.Y.A. analyzed data; T.R.L. wrote the first draft of the paper; T.R.L., M.R.A.-U., M.I.N., and V.Y.A. edited the paper.

This work was supported by National Institutes of Health Grants EY012859, EY030451, and EY005722 to V.Y.A., Grant EY010609 to M.I.N. and M.R.A.-U., and Grant EY029929 to T.R.L.; and Research to Prevent Blindness Inc. Unrestricted Award (Duke University). We thank Ying Hao (Duke Eye Center Electron Microscopy Core Facility) for assistance.

The authors declare no competing financial interests.

Correspondence should be addressed to Muna I. Naash at mnaash@central.uh.edu or Vadim Y. Arshavsky at vadim.arshavsky@duke.edu.

https://doi.org/10.1523/JNEUROSCI.0041-21.2021

Copyright $\odot 2021$ the authors

\section{Introduction}

Vertebrate photoreceptor cells contain a light-sensitive organelle called the outer segment. The outer segment consists of a stack of disc-shaped membranes, or "discs," surrounded by the plasma membrane. New discs are formed as serial plasma membrane evaginations that eventually enclose inside the outer segment (Steinberg et al., 1980; Burgoyne et al., 2015; J. D. Ding et al., 2015; Volland et al., 2015; for review, see Spencer et al., 2020). Disc enclosure is a tightly regulated process allowing the outer segment to maintain its perfect cylindrical shape and size. Yet, the molecular mechanisms governing disc enclosure remain poorly understood.

One protein thought to play a role in the process of disc enclosure is a photoreceptor-specific tetraspanin PRPH2 (also 
known as peripherin-2 or rds), whose mutations cause a heterogeneous set of retinal diseases, including retinitis pigmentosa, pattern dystrophy, and macular dystrophy (Boon et al., 2008; Stenson et al., 2014). PRPH2 forms oligomeric complexes which reside at the rims of enclosed discs where they support the highly curved membrane structure of these rims, essentially allowing the discs to be flat (Arikawa et al., 1992; J. D. Ding et al., 2015; Stuck et al., 2016; Conley et al., 2019; Milstein et al., 2020). In PRPH2 oligomers, noncovalently associated tetramers of PRPH2 are covalently linked among themselves by disulfide bonds (Loewen and Molday, 2000; Chakraborty et al., 2009, 2010; Stuck et al., 2016; Zulliger et al., 2018). While disruption of PRPH2 oligomerization does not completely prevent disc formation (Zulliger et al., 2018) and enclosure (Lewis et al., 2020), it does lead to outer segment dysmorphia (Chakraborty et al., 2009, 2010; Stuck et al., 2014; Conley et al., 2017; Zulliger et al., 2018; Lewis et al., 2020; Milstein et al., 2020).

The goal of this study was to further explore the interconnection between PRPH2 oligomerization and photoreceptor disc enclosure. We studied heterozygous knockin mice bearing either the C150S or the Y141C mutation in PRPH2 that have been shown to affect PRPH2 oligomerization, outer segment ultrastructure, and visual function (Chakraborty et al., 2009, 2010; Stuck et al., 2014; Conley et al., 2017; Zulliger et al., 2018; Lewis et al., 2020). The Y141C mutation, which causes pattern dystrophy in human patients (Khani et al., 2003; Francis et al., 2005; Moshfeghi et al., 2006; Vaclavik et al., 2012), leads to the formation of abnormally large PRPH2 oligomers because of the introduction of additional disulfide bonds between individual PRPH2 molecules (Stuck et al., 2014; Conley et al., 2017). Conversely, the C150S mutation prevents PRPH2 tetramers' assembly into high order, disulfide bond-linked oligomers (Chakraborty et al., 2009, 2010; Zulliger et al., 2018).

We assessed the status of disc enclosure using a recently developed technique for ultrastructural analysis, which yields a more intense staining of newly evaginating "open" discs than mature discs fully enclosed inside the outer segment (J. D. Ding et al., 2015). Applying this technique to C150S and Y141C heterozygous mice revealed that, in both cases, rod outer segments have a significantly increased number of open discs, indicating that PRPH2 oligomerization regulates disc enclosure. The retardation in disc enclosure occasionally results in disc over-elongation, followed by uncontrolled expansion and formation of large membranous "whorls" instead of disc stacks. These data suggest that defects in disc enclosure serve as a primary cause of outer segment dysmorphia in these mice, and likely in patients bearing related $\mathrm{PRPH} 2$ mutations.

\section{Materials and Methods}

Animals. Animal maintenance and experiments were approved by the local Institutional Animal Care and Use Committee (University of Houston) and guidelines as stated by the Association for Research in Vision and Ophthalmology. The generation of the C150S and Y141C knockin mice was previously described by Zulliger et al. (2018) and Stuck et al. (2014), respectively. The $r d s$ mouse was generously provided by Neeraj Agarwal (University of North Texas Health Science Center). All mice were genotyped to ensure that they did not contain either the $r d 8$ (Mattapallil et al., 2012) or $r d 1$ (Pittler et al., 1993) mutations commonly found in inbred mouse strains. All mice were on a pure C57BL/6 genetic background and housed under a 12/12 h diurnal light ( $\sim 30$ lux $)$ cycle.

Transmission electron microscopy (TEM). Fixation and processing of mouse eyes for TEM were performed as described previously (J. D. Ding et al., 2015). In the afternoon, anesthetized mice were transcardially perfused with $2 \%$ PFA, $2 \%$ glutaraldehyde, and $0.05 \%$ calcium chloride in $50 \mathrm{~mm}$ MOPS, $\mathrm{pH} 7.4$, resulting in exsanguination. Enucleated eyes were fixed for an additional $2 \mathrm{~h}$ in the same fixation solution at room temperature. Eyecups were dissected from fixed eyes, embedded in 2.5\% low-melt agarose (Precisionary), and cut into $200-\mu \mathrm{m}$ thick slices on a Vibratome (VT1200S; Leica Microsystems). Agarose sections were stained with $1 \%$ tannic acid (Electron Microscopy Sciences) and 1\% uranyl acetate (Electron Microscopy Sciences), gradually dehydrated with ethanol, and infiltrated and embedded in Spurr's resin (Electron Microscopy Sciences); $70 \mathrm{~nm}$ sections were cut, placed on copper grids, and counterstained with $2 \%$ uranyl acetate and 3.5\% lead citrate (19314; Ted Pella). The samples were imaged on a JEM-1400 electron microscope (JEOL) at $60 \mathrm{kV}$ with a digital camera (Orius; Gatan). Image analysis and processing was performed with ImageJ.

Western blots of retinal lysates. Eyecups were dissected and immediately frozen using liquid nitrogen and stored at $-80^{\circ} \mathrm{C}$ before processing. Lysates were prepared as previously described (Stuck et al., 2014). In short, eyecups were lysed in solubilization buffer (PBS, pH 7.0, containing $1 \%$ Triton X-100, $5 \mathrm{~mm}$ EDTA, $5 \mathrm{mg} / \mathrm{ml} \mathrm{NEM}$, and protease inhibitors, Roche) on ice. Samples were incubated on ice for $1 \mathrm{~h}$ before being centrifuged for $30 \mathrm{~min}$ at $18,000 \times \mathrm{g}$ at $4^{\circ} \mathrm{C}$. Protein concentration was assayed by using a colorimetric Bradford assay (Bio-Rad). Western blotting was performed as previously described (Chakraborty et al., 2008) with minor modifications. Lysates were incubated for $30 \mathrm{~min}$ with Laemmli sample buffer (50 mm Tris-HCl, 2\% SDS, 10\% glycerol, and 1\% bromophenol blue) with or without $100 \mathrm{~mm}$ DTT (for reducing or nonreducing SDS-PAGE, respectively). Samples containing $10 \mu \mathrm{g}$ of total protein were run on a $10 \%$ SDS-PAGE gel, transferred onto a PVDF membrane, and blocked with $5 \%$ nonfat dry milk in TBS with $0.1 \%$ Tween-20. Blots were incubated with primary antibodies, including 2B7 monoclonal mouse anti-PRPH2 (Conley et al., 2019) (Millipore), 2H5 monoclonal mouse anti-ROM1 (Kakakhel et al., 2020) (Millipore), and AC-15 monoclonal mouse anti- $\beta$-actin conjugated to HRP (Millipore) for $2 \mathrm{~h}$ before washing and incubating with goat anti-mouse HRP (Millipore) for $2 \mathrm{~h}$ (except in the case of $\beta$-actin). All experiments were repeated at least 3 times. Blots were imaged using ChemiDoc MP imaging system (Bio-Rad).

Velocity sedimentation using sucrose gradients. Eyecups were dissected and immediately frozen using liquid nitrogen and stored at $-80^{\circ}$ $\mathrm{C}$ before processing. Lysates were prepared essentially as described above (Stuck et al., 2014). In short, individual eyecups were lysed in $200 \mu \mathrm{l} \mathrm{sol-}$ ubilization buffer (PBS, pH 7.0, containing 1\% Triton X-100, 5 m EDTA, $5 \mathrm{mg} / \mathrm{ml} \mathrm{NEM}$, and protease inhibitors, Roche) on ice. Samples were incubated on ice for $1 \mathrm{~h}$ before being centrifuged for $30 \mathrm{~min}$ at $20,000 \times g$ at $4^{\circ} \mathrm{C}$. Sucrose gradients were prepared as previously described (Chakraborty et al., 2009). In short, continuous gradients of $5 \%-20 \%$ sucrose were prepared by sequentially layering $0.5 \mathrm{ml}$ each of $20 \%, 15 \%, 10 \%$, and $5 \%$ sucrose solutions in PBS with $0.1 \%$ Triton X100 and $10 \mathrm{~mm}$ NEM and allowing them to sit at room temperature for 1 $\mathrm{h}$ to become continuous. Sucrose gradients were then chilled on ice for $30 \mathrm{~min}$ before loading lysate and centrifugation at $40,000 \mathrm{rpm}$ on a TLS55 swinging bucket rotor (Beckman Coulter) for $16 \mathrm{~h}$ at $4^{\circ} \mathrm{C}$. The bottom of each gradient was pierced with a $21 \mathrm{G}$ needle, and 12 fractions of $\sim 180 \mu$ l each were collected. Western blotting was performed essentially as previously described (Spencer et al., 2016). In short, lysates were incubated with Laemmli sample buffer (50 mM Tris- $\mathrm{HCl}, 2 \%$ SDS, $10 \%$ glycerol, and $1 \%$ bromophenol blue) with or without $100 \mathrm{~mm}$ DTT for reducing or nonreducing blots, respectively. Reduced samples were incubated at $90^{\circ} \mathrm{C}$ for $5 \mathrm{~min}$, whereas nonreduced samples were incubated at room temperature for $10 \mathrm{~min}$. Reduced samples were run on a $10 \%-20 \%$ Tris- $\mathrm{HCl}$ gel, whereas nonreduced samples were run on a $10 \%$ Tris- $\mathrm{HCl}$ gel. Gels were transferred onto PVDF membrane and blocked with Intercept (PBS) Blocking Buffer (Li-Cor) with $0.25 \%$ Tween-20. Blots were incubated with polyclonal rabbit anti-PRPH2 (Gabriel Travis, University of California, Los Angeles) overnight at $4^{\circ} \mathrm{C}$ before washing and incubating with donkey anti-rabbit DyLight 800 (Invitrogen) for $2 \mathrm{~h}$. All experiments were repeated at least 3 times. Blots were imaged using Odyssey CLx imaging system (Li-Cor). 
Experimental design and statistical analysis. For the quantification of the number of open discs (see Fig. 1C), darkly stained new discs at the base of the rod outer segment were counted until the first lightly stained enclosed disc. Three retinas were collected of each genotype with the number of outer segments analyzed as follows: WT1, 32; WT2, 45; WT3, 34; rds/+1, 26; $r d s /+2,18 ; r d s /+3,23 ; \mathrm{C} 150 \mathrm{~S} /+1,32 ;$ $\mathrm{C} 150 \mathrm{~S} /+2,56 ; \mathrm{C} 150 \mathrm{~S} /+3,33 ; \mathrm{Y} 141 \mathrm{C} /+1,57$; $\mathrm{Y} 141 \mathrm{C} /+2,62$; $\mathrm{Y} 141 \mathrm{C} /+3,33$. Data were plotted with samples separated, while statistical analysis was performed on combined samples with sample sizes as follows: WT, 111; rds/+, 67; $\mathrm{C} 150 \mathrm{~S} /+, 121 ; \mathrm{Y} 141 \mathrm{C} /+, 152$. One-way ANOVA was performed to determine statistical significance across genotypes $(p<0.0001)$ followed by Tukey's multiple comparisons analysis, which was performed to determine statistical significance between individual genotypes in each fraction (significance values reported in legends).

Densitometric analysis of nonsaturated bands from Western blots (see Figs. 2, 3) was performed using Image Lab software version 4.1 (Bio-Rad) and ImageJ. For the quantification of PRPH2 and ROM1 levels following reducing SDS-PAGE (see Fig. $2 A, B$ ), data were normalized to $\beta$-actin loading control. For PRPH2 levels, the number of eyecups analyzed was as follows: WT, $4 ; r d s /+, 4$; C150S/+, 5; $\mathrm{Y} 141 \mathrm{C} /+, 4$. One-way ANOVA was performed to determine statistical significance across genotypes ( $p=0.0084$; ROM1, $p=0.1213)$, followed by Dunnett's multiple comparisons post hoc test to determine statistical significance between individual genotypes and WT (significance values reported in legends). For ROM1 levels, the number of eyecups analyzed was as follows: WT, 5 ; $r d s /+, 4$; C150S/+, 5; Y141C/ ,+ 5 . One-way ANOVA was performed to determine statistical significance across genotypes $(p=0.1213)$. For the quantification of PRPH2 and ROM1 monomer, dimer, and high order oligomer bands following nonreducing SDS-PAGE (see Fig. 2C,D), three samples were used for all genotypes. Two-way ANOVA was performed to determine statistical significance across genotypes and complexes (PRPH2, $p<0.0001$; ROM1, $p=0.5702$ ), followed by Dunnett's multiple comparisons post hoc test in the case of PRPH2 to determine statistical significance between individual genotypes and WT (significance values reported in legends). For the velocity sedimentation analysis of $\mathrm{PRPH} 2$ supramolecular organization (see Fig. 3B), three samples were used for all genotypes. Two-way ANOVA was performed to determine statistical significance across genotypes and fractions $(p=0.0172)$, followed by Dunnett's multiple comparisons post hoc test to determine statistical significance between individual genotypes and WT in each fraction (significance values reported in legends).

All experiments were performed with mice of randomized sex. Data were graphed with Prism 7 (GraphPad) with error bars indicating the SEM. Statistical analyses were performed using Prism 7 (GraphPad). Where noted, statistical values are depicted in graphs (noted in figure legends).

\section{Results}

The status of photoreceptor disc enclosure was analyzed in C150S and Y141C heterozygous mice (C150S/+ and Y141C/+, respectively) at $\mathrm{P} 16$, an age preceding the development of severe outer segment dysmorphia (Stuck et al., 2014; Conley et al., 2017; Zulliger et al., 2018). For ultrastructural analysis, we contrasted tissue with tannic acid and uranyl acetate (J. D. Ding et al., 2015). Because tannic acid poorly penetrates membranes, this procedure results in a preferential, darker staining of "open" disc membranes exposed to the extracellular space than membranes of discs fully enclosed inside the outer segment. Images obtained at lower magnification showed that a majority of outer segments in both heterozygous mutant mice appear relatively normal in regard to their overall shape and disc structure, especially when compared with those in $r d s$ heterozygous mice ( $r d s /+)$ bearing a null PRPH2 allele (van Nie et al., 1978; Connell et al., 1991; Travis et al., 1991) (Fig. 1A). Yet, some dysmorphic outer segments were observed in both $\mathrm{C} 150 \mathrm{~S} /+$ and $\mathrm{Y} 141 \mathrm{C} /+$ mice even at this early age.

Examining C150S/+ and $\mathrm{Y} 141 \mathrm{C} /+$ photoreceptors at higher magnification revealed a striking phenotype not observed in any 

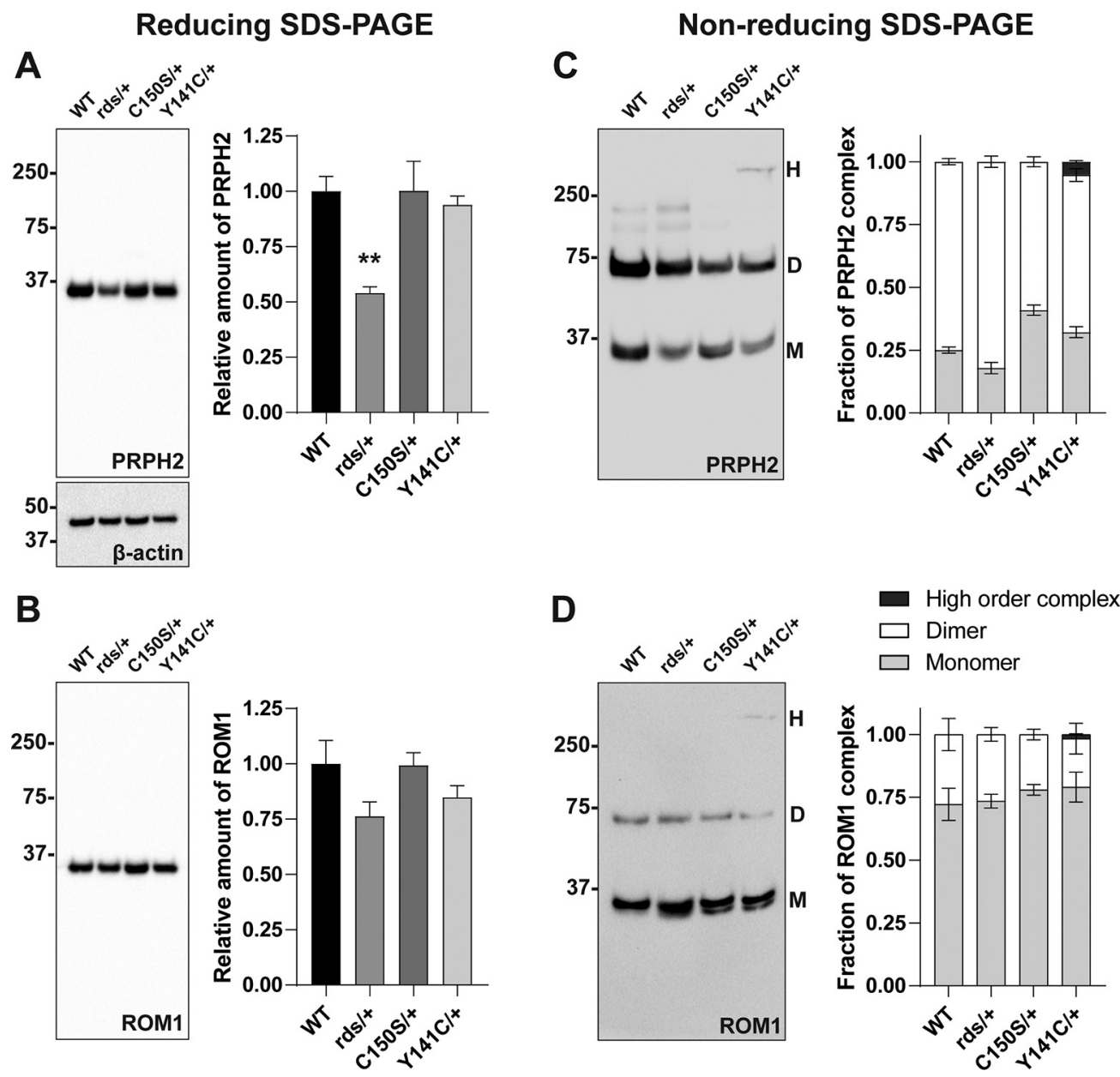

Figure 2. The C150S and Y141C heterozygous mutations affect PRPH2 supramolecular organization without causing a significant reduction in the PRPH2 expression level. $\boldsymbol{A}, \boldsymbol{B}, \mathrm{A}$ single Western blot probed for both PRPH2 and ROM1 after protein separation by SDS-PAGE under reducing conditions. Each sample contained $10 \mu \mathrm{g}$ of lysate obtained from eyecups of WT, $r d s /+$, $\mathrm{C150S/+}$, or Y141C/+ collected at P16. The amount of PRPH2 and ROM1 was quantified on the same blot using densitometry of at least four independent samples, normalized to $\beta$-actin as a loading control and plotted in the graph on the right relative to WT. One-way ANOVA with Dunnett's multiple comparisons post hoc test revealed a statistically significant reduction in PRPH2 for $r d s /+\left({ }^{* *} p=0.0096\right)$ but not $\mathrm{C} 150 \mathrm{~S} /+$ or $\mathrm{Y} 141 \mathrm{C} /+$ eyecups $(p=0.9999$ and $p=0.9346$, respectively), while there was no statistical significance in ROM1 levels. $\boldsymbol{C}, \boldsymbol{D}, \mathrm{A}$ single Western blot probed for PRPH2 and ROM1 performed after protein separation by SDS-PAGE under nonreducing conditions. Each sample contained $10 \mu \mathrm{g}$ of lysate obtained from eyecups of WT, rds/ + , $\mathrm{C} 150 \mathrm{~S} /+$, or $\mathrm{Y} 141 \mathrm{C} /+$ collected at P16. Under these conditions, PRPH2 and ROM1 run as abnormal high order complexes $(\mathrm{H},>250 \mathrm{kDa})$, dimers $(\mathrm{D}, \sim 75 \mathrm{kDa})$, and monomers $(\mathrm{M}, \sim 37$ $\mathrm{kDa}$ ). Protein amount in each band was quantified using densitometry of three independent samples and plotted in the graph on the right. Two-way ANOVA with Dunnett's multiple comparisons post hoc test revealed that more PRPH2 exists as a monomer than dimer in C150S/+ eyecups (monomer, $p<0.0001$; dimer, $p<0.0001$ ) as well as smaller changes in both $r d s /+$ (monomer, $p=0.0243$; dimer, $p=0.0243$ ) and $\mathrm{Y} 141 \mathrm{C} /+$ eyecups (monomer, $p<0.0001$, dimer, $p=0.0002$ ), while there was no statistical significance in any differences in R0M1 complexes. The high order complex that includes both PRPH2 and ROM1 was only observed in $\mathrm{Y} 141 \mathrm{C} /+$ eyecups.

previously characterized mutant photoreceptors: the number of open discs forming at the base of the otherwise normal-looking rod outer segments was significantly increased in both mice (Fig. $1 B, C$ ). Whereas WT rods contained a relatively constant number of $\sim 7-10$ open discs, $\mathrm{C} 150 \mathrm{~S} /+$ and $\mathrm{Y} 141 \mathrm{C} /+$ rods contained an average of $\sim 14$ and $\sim 18$ open discs, respectively. In addition, the number of open discs in these mutants was much more variable than in WT rods. We observed as many as 27 open discs in $\mathrm{C} 150 \mathrm{~S} /+$ rods and 47 in $\mathrm{Y} 141 \mathrm{C} /+$ rods (one such extreme example is shown in Fig. $1 D)$. In contrast, the largest number of open discs in a WT rod was 14.

In principle, the increased number of open discs in C150S/+ and $\mathrm{Y} 141 \mathrm{C} /+$ rods could be potentially explained by a reduction in the overall content of PRPH2. However, no such decrease was observed in either mouse (Fig. 2A). Furthermore, the number of open discs in the subset of relatively normal-looking outer segments of $r d s /+$ mice, which express approximately half of the WT PRPH2 amount (Fig. 2A) (see also Cheng et al., 1997), is slightly lower than in WT rods (Fig. $1 B, C$ ). We additionally analyzed the levels of ROM1, a tetraspanin binding partner of PRPH2 (Loewen and Molday, 2000; Stuck et al., 2016), and found no significant differences across all genotypes (Fig. 2B). These data suggest that the observed impairment in disc enclosure is a specific consequence of the C150S and Y141C mutations.

As described above, mice bearing the C150S and Y141C mutations are characterized by abnormal PRPH2 oligomerization (Stuck et al., 2014; Conley et al., 2017; Zulliger et al., 2018). To assess the status of PRPH2 oligomerization in C150S/+ and Y141C/+ rods at P16, we used nonreducing SDS-PAGE (Chakraborty et al., 2008) (Fig. 2C). In this assay, PRPH2 oligomers are denatured into two forms: dimers originating from complexes that are covalently linked through disulfide bonds (i.e., larger than tetramers) and monomers originating from noncovalent tetrameric complexes. Consistent with previous reports, $\mathrm{C} 150 \mathrm{~S} /+$ mice displayed a decrease in the PRPH2 dimer-to-monomer ratio $(\sim 1.5$ vs $\sim 3$ in 
A

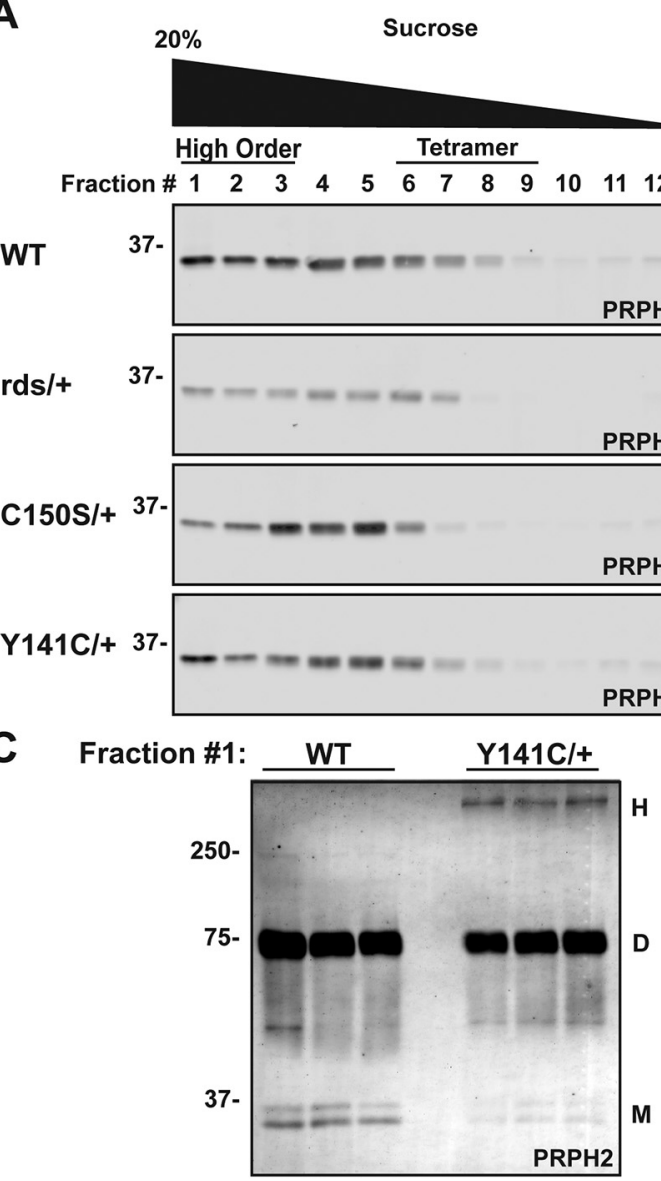

B
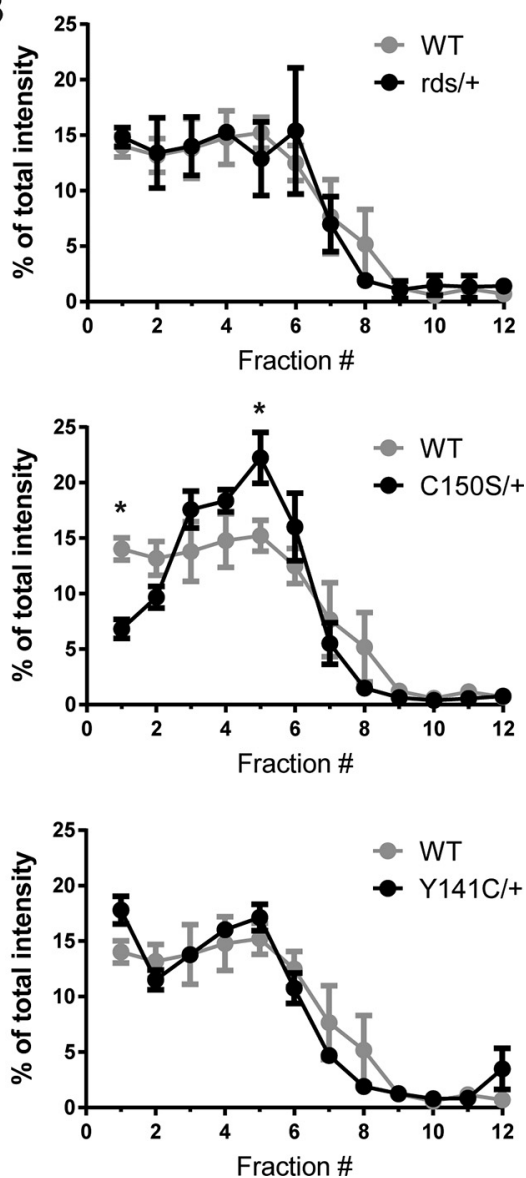

Figure 3. Velocity sedimentation analysis of PRPH2 supramolecular organization in $r d s /+, C 150 S /+$, and $\mathrm{Y} 141 \mathrm{C} /+$ retinal lysates. A, Lysates obtained under nonreducing conditions from eyecups of WT, rds/+, C150S/+, and Y141C/+ mice at P16 were subjected to velocity sedimentation on 5\%-20\% sucrose gradients. Twelve fractions were collected with fraction \#1 corresponding to $20 \%$ sucrose and fraction \#12 to 5\% sucrose. Proteins from each fraction were subjected to reducing SDS-PAGE and Western blotting for PRPH2. B, Quantification of PRPH2 in each fraction was performed using densitometry of three independent lysates and normalized to the total PRPH2 content across all fractions. Two-way ANOVA with Dunnett's multiple comparisons post hoc test revealed a statistically significant change in PRPH2 content of two fractions from C150S/+ lysates: a reduction in high order oligomers in fraction \#1 ( $\left.{ }^{*} p=0.0124\right)$ and a corresponding increase in smaller PRPH2 complexes in fraction \#5 $\left(^{*} p=0.0156\right)$. C, Proteins obtained from fraction \#1 of three independently sedimented WT and Y141C/+ samples were separated by SDS-PAGE under nonreducing conditions and Western blotted for PRPH2. Under these conditions, PRPH2 runs predominantly as a dimer $(\mathrm{D}, \sim 75 \mathrm{kDa})$ with very few monomers $(\mathrm{M}, \sim 37$ kDa). Abnormal, high order complexes ( $\mathrm{H},>250 \mathrm{kDa}$ ) exist only in the $\mathrm{Y} 141 \mathrm{C} /+$ sample.

WT mice), indicative of a smaller outer segment content of disulfide-bridged PRPH2 oligomers (Zulliger et al., 2018). Meanwhile, Y141C/ + mice displayed a small fraction ( $~ 5 \%$ of total PRPH2) of abnormally large $(>250 \mathrm{kDa})$ oligomeric complexes of both PRPH2 and ROM1 (Fig. 2D), also as reported previously (Stuck et al., 2014; Conley et al., 2017). These complexes are formed through numerous ectopic disulfide bonds because of the presence of an additional cysteine. Of note, these abnormally large oligomeric complexes were not observed in any other genotypes assessed.

To further characterize the supramolecular organization of $\mathrm{PRPH} 2$ in these mice, we separated PRPH2 complexes of various sizes using velocity sedimentation of retinal lysates on a sucrose gradient under nonreducing conditions, followed by SDS-PAGE under reducing conditions and Western blotting for PRPH2 (Clarke et al., 2000; Goldberg et al., 2001; X. Q. Ding et al., 2004; Chakraborty et al., 2008, 2009; Stuck et al., 2014; Zulliger et al., 2018; Milstein et al., 2020) (Fig. 3A). In this technique, high order oligomeric complexes of PRPH2 sediment in fractions \#13, while tetramers sediment in fractions \#6-9 (Chakraborty et al., 2008; Stuck et al., 2014). As quantified in Figure 3B, PRPH2 had a relatively even distribution among the fractions corresponding to oligomeric and tetrameric forms in both the WT and $r d s /+$ retinas, illustrating that merely a reduction in the content of WT
PRPH2 does not affect its supramolecular organization. In contrast, C150S/+ retinas contained a reduced amount of high order PRPH2 oligomers (i.e., fraction \#1) with a corresponding increase in smaller complexes (i.e., fraction \#5). In Y141C/+ retinas, the change in supramolecular PRPH2 organization was modest and consisted of a reproducible, although not statistically significant, increase in the PRPH2 amount in fraction \#1 containing the largest oligomers. This small increase is consistent with $\sim 5 \%$ of PRPH2 existing in abnormal high order complexes (Fig. 2C), also observed in fraction \#1 analyzed by nonreducing SDS-PAGE (Fig. 3C).

Together, the data in Figures 2 and 3 show that: (1) rds/+ retinas do not appear to have any change in PRPH2 supramolecular organization; (2) C150S/ + retinas have a reduction in high order PRPH2 oligomers; and (3) Y141C/ + retinas contain a small population of abnormally large $\mathrm{PRPH} 2$ oligomeric complexes corresponding to only $\sim 4 \%-5 \%$ of total PRPH2. These data suggest that the defects in disc enclosure associated with the C150S and Y141C mutations originate from abnormal supramolecular organization of $\mathrm{PRPH} 2$ rather than altered $\mathrm{PRPH} 2$ content.

While the defect in disc enclosure was the most striking phenotype observed in young C150S and Y141C heterozygotes, each line contained a small population of photoreceptors that 

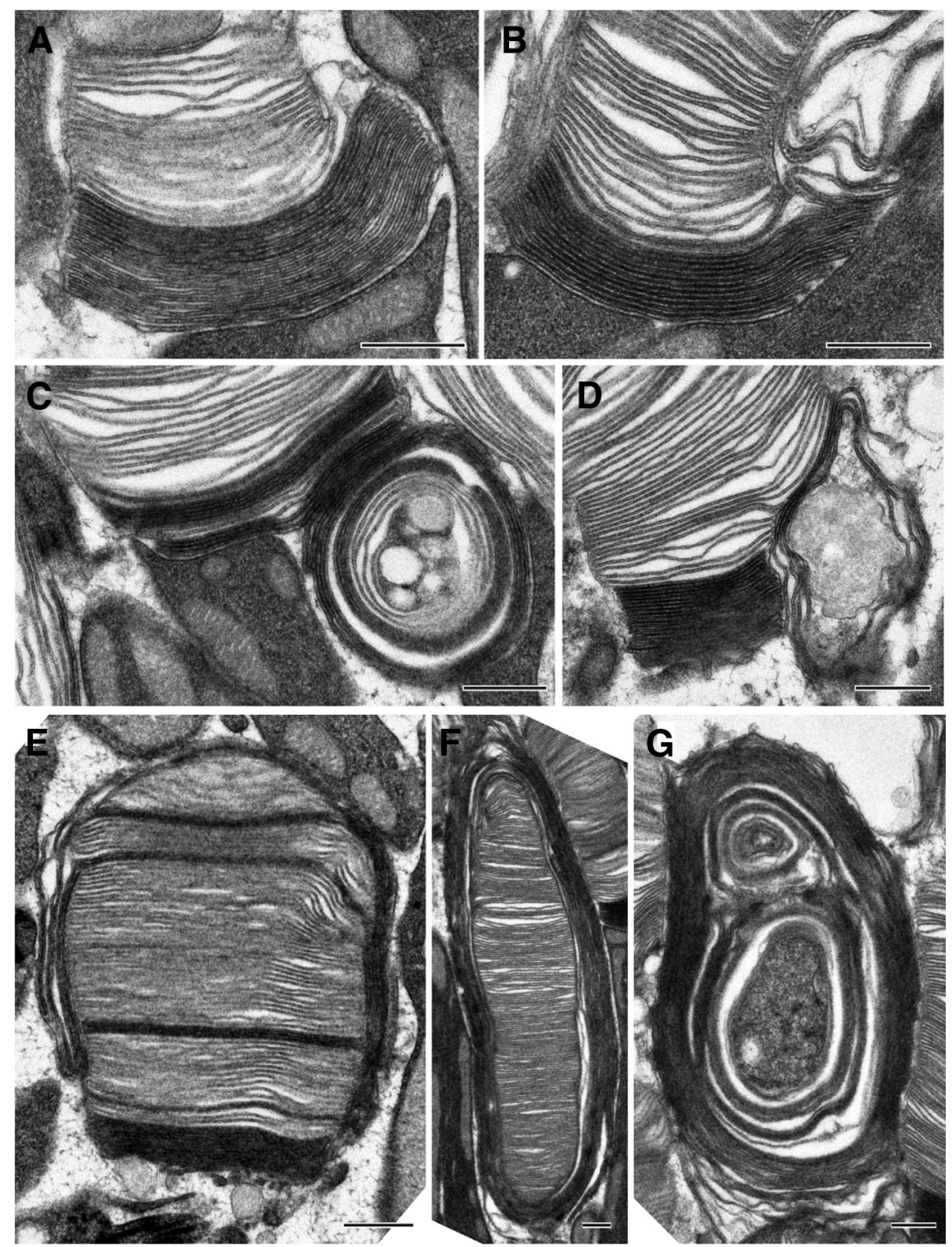

Figure 4. $\quad(150 \mathrm{~S} /+$ mice exhibit a stepwise progression of defects in disc enclosure leading to the formation of membranous whorls. A-G, Representative TEM images of tannic acid/uranyl acetate-stained retinas of C150S/+ mice at P16. Outer segment structural defects ranged from slightly overgrown open discs to membranous whorls. On occasion, overgrown membrane structures extend laterally across the outer segment giving the appearance of open discs in the middle of the outer segment $(\boldsymbol{E})$. Scale bars, $0.5 \mu \mathrm{m}$.

exhibited more extensive morphologic abnormalities even at P16. C150S/ + mice contained cells in which newly forming discs were longer than normal (Fig. $4 A, B$ ). In other cells, these longer discs were dramatically overgrown and enveloped other cellular structures, including neighboring cells (Fig. 4C,D). On occasion, the overgrown disc membranes extended around the entire outer segment (Fig. 4E,F) or formed membrane whorls (Fig. $4 G$ ), such as previously observed in older C150S mice (Zulliger et al., 2018). The same diversity of outer segment dysmorphia, from overextended nascent discs to membranous whorls, was observed in $\mathrm{Y} 141 \mathrm{C} /+$ mice (Fig. 5). Interestingly, in both mutants, overgrown discs appear to grow to exactly the same length together (e.g., Figs. $4 A, 5 C$ ), suggesting that the diameter of a disc may be templated from adjacent ones.

\section{Discussion}

While previous studies established that PRPH2 plays a critical role in stabilizing the disc rim structure (Arikawa et al., 1992; Kevany et al., 2013; J. D. Ding et al., 2015; Stuck et al., 2016;
Milstein et al., 2017; Salinas et al., 2017; Conley et al., 2019; Milstein et al., 2020), the data reported here suggest that $\mathrm{PRPH} 2$ also plays an active role in the membrane remodeling that takes place during disc enclosure. Our central finding is that the defects in PRPH2 oligomerization caused by the C150S and Y141C mutations are associated with an increased number of newly forming, not-yet-enclosed discs, as well as an unusually high variability in the number of not-yet-enclosed discs across individual rod cells. Remarkably, this phenomenon was observed regardless of whether the extent of PRPH2 oligomerization was decreased or increased. Furthermore, an alteration in oligomerization of only $\sim 5 \% \mathrm{PRPH} 2$ in $\mathrm{Y} 141 \mathrm{C} /+$ mice was sufficient to produce a major phenotype. This suggests that the process of $\mathrm{PRPH} 2$ oligomerization proceeds with such a precise speed and high fidelity that even an occasional formation of an abnormal disulfide bond may be sufficient to derail normal disc enclosure dynamics. Our data further suggest that the precise regulation of disc enclosure is essential for achieving the uniformity in the final diameter of enclosed discs and, accordingly, the outer segment as a whole.

Ultimately, outer segments of C150S/+ and $\mathrm{Y} 141 \mathrm{C} /+$ mice become dysmorphic and photoreceptors degenerate. The incremental array of structural defects observed in young mice suggests a sequence of events leading to pathology in these and potentially other PRPH2 mutant mice. As discs remain open for an abnormally long period of time, they occasionally incorporate more than a normal amount of membranous material delivered to the outer segment, causing disc overgrowth comparable to that observed in other models (e.g., Yang et al., 2008; Schietroma et al., 2017; Sharif et al., 2018; Spencer et al., 2019; Carr et al., 2021). This disc overgrowth can become uncontrolled, leading to the formation of "membrane whorl" structures described for other mutations in PRPH2 (Hawkins et al., 1985; Tam et al., 2004; Chakraborty et al., 2016, 2020; Lewis et al., 2020) and other proteins (LaVail et al., 1972; Narfström and Nilsson, 1989; Leon and Curtis, 1990; White et al., 1993; Stiemke et al., 1994; Jablonski et al., 1999; Gao et al., 2002; Yefimova et al., 2002; Duncan et al., 2003; Rice et al., 2004; Lu et al., 2019; Spencer et al., 2019; Ying et al., 2019). The probability of whorl formation reflects the nature of disc formation defect. For instance, whorl formation is predominant in rods unable to initiate new disc formation because of the $\mathrm{KO}$ of the actin nucleator complex Arp2/3 (Spencer et al., 2019), but is much less prominent in the current PRPH2 mutants in which new discs are formed and, for the most part, manage to enclose. Interestingly, even extremely dysmorphic whorls may contain enclosed membrane structures (e.g., Fig. 5G), as has been observed in mice bearing other PRPH 2 mutations (Lewis et al., 2020) and in the Arp $2 / 3$ KO (Spencer et al., 2019).

Critical for documenting the novel phenotypes of C150S/+ and $\mathrm{Y} 141 \mathrm{C} /+$ mice were several methodological approaches used in this study, such as using mice bearing only a single copy 
of the C150S and Y141C mutant alleles and analyzing them at an early age. Indeed, older heterozygotes and mice homozygous for each mutation have outer segments too perturbed to appreciate a fine change in the number of open discs (Stuck et al., 2014; Conley et al., 2017; Zulliger et al., 2018; Lewis et al., 2020). Most importantly, a definitive distinction between open and enclosed discs could be made by contrasting the tissue with tannic acid/uranyl acetate versus traditionally used osmium tetroxide.

Of note, the number of open discs in WT mouse rods observed in this study is consistent with the original report introducing the tannic acid methodology (J. D. Ding et al., 2015), but is higher than the 4-6 discs reported for mouse rods in another study that used osmium tetroxide (Volland et al., 2015). This discrepancy is likely explained by the fact that tannic acid staining unequivocally identifies all discs that are not $100 \%$ enclosed, while certain discs undergoing the process of enclosure may appear as enclosed in thin single plane sections, as the authors discussed (Volland et al., 2015).

Another observation from the current study is that $\mathrm{C} 150 \mathrm{~S} /+$ photoreceptors do not form "ectopic incisures" or "ectopic disc rims," a phenotype recently reported for frog rods transgenically expressing the C150S PRPH2 mutant (Milstein et al., 2020). There are two potential explanations for this discrepancy. First, mouse rods have only a single incisure (De Robertis, 1956; Cohen, 1960), whereas frog rods have approximately two dozen incisures (Tsukamoto, 1987). Thus, the presence of ectopic incisures in $\mathrm{C} 150 \mathrm{~S}$ transgenic frogs, but not $\mathrm{C} 150 \mathrm{~S} /+$ mice, could be a species-dependent phenotype based on differences in incisure formation. Second, it is possible that the ectopic incisures and disc rims in frogs occurred because the C150S mutant was expressed in addition to the normal level of endogenous PRPH2, whereas knockin C150S/+ mice have essentially normal total PRPH2 content.

In conclusion, the data presented in this study suggest that PRPH2 plays an active role in the process of photoreceptor disc enclosure and that defects in disc enclosure may be the primary cause of outer segment dysmorphia that arises from these, and possibly other, $\mathrm{PRPH} 2$ mutations. Yet, much remains to be learned about the underlying mechanisms and other aspects of disc enclosure. For example, it is completely unknown how the transition from disc evagination to enclosure is triggered on the molecular level. Regardless, it does not appear that this transition is tightly bound to the number of newly forming discs, as this number varies by nearly twofold during the normal diurnal cycle (Volland et al., 2015) without affecting the disc/outer segment diameter. Another interesting question relates to a well-recognized difference between mammalian rods and cones, whereby all mature discs in rods are fully enclosed while cone discs may remain partially open (Cohen, 1970; Anderson et al., 1978; Bunt, 1978; Carter-Dawson and LaVail, 1979). These exciting questions remain the subject of future investigations.

\section{References}

Anderson DH, Fisher SK, Steinberg RH (1978) Mammalian cones: disc shedding, phagocytosis, and renewal. Invest Ophthalmol Vis Sci 17:117-133.

Arikawa K, Molday LL, Molday RS, Williams DS (1992) Localization of peripherin/rds in the disk membranes of cone and rod photoreceptors: relationship to disk membrane morphogenesis and retinal degeneration. J Cell Biol 116:659-667.

Boon CJ, den Hollander AI, Hoyng CB, Cremers FP, Klevering BJ, Keunen JE (2008) The spectrum of retinal dystrophies caused by mutations in the peripherin/RDS gene. Prog Retin Eye Res 27:213-235.

Bunt AH (1978) Fine structure and radioautography of rabbit photoreceptor cells. Invest Ophthalmol Vis Sci 17:90-104.

Burgoyne T, Meschede IP, Burden JJ, Bailly M, Seabra MC, Futter CE (2015) Rod disc renewal occurs by evagination of the ciliary plasma membrane that makes cadherin-based contacts with the inner segment. Proc Natl Acad Sci USA 112:15922-15927.

Carr BJ, Stanar P, Moritz OL (2021) Distinct roles for prominin-1 and photoreceptor cadherin in outer segment disc morphogenesis in CRISPRaltered X. laevis. J Cell Sci 134:jcs253906. 
Carter-Dawson LD, LaVail MM (1979) Rods and cones in the mouse retina: I. Structural analysis using light and electron microscopy. J Comp Neurol 188:245-262.

Chakraborty D, Ding XQ, Fliesler SJ, Naash MI (2008) Outer segment oligomerization of RDS: evidence from mouse models and subcellular fractionation. Biochemistry 47:1144-1156.

Chakraborty D, Ding XQ, Conley SM, Fliesler SJ, Naash MI (2009) Differential requirements for retinal degeneration slow intermolecular disulfide-linked oligomerization in rods versus cones. Hum Mol Genet 18:797-808.

Chakraborty D, Conley SM, Stuck MW, Naash MI (2010) Differences in RDS trafficking, assembly and function in cones versus rods: insights from studies of C150S-RDS. Hum Mol Genet 19:4799-4812.

Chakraborty D, Conley SM, Zulliger R, Naash MI (2016) The K153Del PRPH2 mutation differentially impacts photoreceptor structure and function. Hum Mol Genet 25:3500-3514.

Chakraborty D, Strayve DG, Makia MS, Conley SM, Kakahel M, Al-Ubaidi MR, Naash MI (2020) Novel molecular mechanisms for Prph2-associated pattern dystrophy. FASEB J 34:1211-1230.

Cheng T, Peachey NS, Li S, Goto Y, Cao Y, Naash MI (1997) The effect of peripherin/rds haploinsufficiency on rod and cone photoreceptors. J Neurosci 17:8118-8128.

Clarke G, Goldberg AF, Vidgen D, Collins L, Ploder L, Schwarz L, Molday LL, Rossant J, Szel A, Molday RS, Birch DG, McInnes RR (2000) Rom-1 is required for rod photoreceptor viability and the regulation of disk morphogenesis. Nat Genet 25:67-73.

Cohen AI (1960) The ultrastructure of the rods of the mouse retina. Am J Anat 107:23-48.

Cohen AI (1970) Further studies on the question of the patency of saccules in outer segments of vertebrate photoreceptors. Vision Res 10:445-453.

Conley SM, Stuck MW, Watson JN, Naash MI (2017) Rom1 converts Y141C-Prph2-associated pattern dystrophy to retinitis pigmentosa. Hum Mol Genet 26:509-518.

Conley SM, Stuck MW, Watson JN, Zulliger R, Burnett JL, Naash MI (2019) Prph2 initiates outer segment morphogenesis but maturation requires Prph2/Rom1 oligomerization. Hum Mol Genet 28:459-475.

Connell G, Bascom R, Molday L, Reid D, McInnes RR, Molday RS (1991) Photoreceptor peripherin is the normal product of the gene responsible for retinal degeneration in the rds mouse. Proc Natl Acad Sci USA 88:723-726.

De Robertis E (1956) Electron microscope observations on the submicroscopic organization of the retinal rods. J Biophys Biochem Cytol 2:319330 .

Ding JD, Salinas RY, Arshavsky VY (2015) Discs of mammalian rod photoreceptors form through the membrane evagination mechanism. J Cell Biol 211:495-502.

Ding XQ, Nour M, Ritter LM, Goldberg AF, Fliesler SJ, Naash MI (2004) The $\mathrm{R} 172 \mathrm{~W}$ mutation in peripherin/rds causes a cone-rod dystrophy in transgenic mice. Hum Mol Genet 13:2075-2087.

Duncan JL, LaVail MM, Yasumura D, Matthes MT, Yang H, Trautmann N, Chappelow AV, Feng W, Earp HS, Matsushima GK, Vollrath D (2003) An RCS-like retinal dystrophy phenotype in mer knockout mice. Invest Ophthalmol Vis Sci 44:826-838.

Francis PJ, Schultz DW, Gregory AM, Schain MB, Barra R, Majewski J, Ott J, Acott T, Weleber RG, Klein ML (2005) Genetic and phenotypic heterogeneity in pattern dystrophy. Br J Ophthalmol 89:1115-1119.

Gao J, Cheon K, Nusinowitz S, Liu Q, Bei D, Atkins K, Azimi A, Daiger SP, Farber DB, Heckenlively JR, Pierce EA, Sullivan LS, Zuo J (2002) Progressive photoreceptor degeneration, outer segment dysplasia, and rhodopsin mislocalization in mice with targeted disruption of the retinitis pigmentosa-1 (Rp1) gene. Proc Natl Acad Sci USA 99:5698-5703.

Goldberg AF, Fales LM, Hurley JB, Khattree N (2001) Folding and subunit assembly of photoreceptor peripherin/rds is mediated by determinants within the extracellular/intradiskal EC2 domain: implications for heterogeneous molecular pathologies. J Biol Chem 276:42700-42706.

Hawkins RK, Jansen HG, Sanyal S (1985) Development and degeneration of retina in rds mutant mice: photoreceptor abnormalities in the heterozygotes. Exp Eye Res 41:701-720.

Jablonski MM, Wohabrebbi A, Ervin CS (1999) Lactose promotes organized photoreceptor outer segment assembly and preserves expression of photoreceptor proteins in retinal degeneration. Mol Vis 5:16.
Kakakhel M, Tebbe L, Makia MS, Conley SM, Sherry DM, Al-Ubaidi MR, Naash MI (2020) Syntaxin 3 is essential for photoreceptor outer segment protein trafficking and survival. Proc Natl Acad Sci USA 117:2061520624.

Kevany BM, Tsybovsky Y, Campuzano ID, Schnier PD, Engel A, Palczewski K (2013) Structural and functional analysis of the native peripherinROM1 complex isolated from photoreceptor cells. J Biol Chem 288: 36272-36284

Khani SC, Karoukis AJ, Young JE, Ambasudhan R, Burch T, Stockton R, Lewis RA, Sullivan LS, Daiger SP, Reichel E, Ayyagari R (2003) Late-onset autosomal dominant macular dystrophy with choroidal neovascularization and nonexudative maculopathy associated with mutation in the RDS gene. Invest Ophthalmol Vis Sci 44:3570-3577.

LaVail MM, Sidman RL, O’Neil D (1972) Photoreceptor-pigment epithelial cell relationships in rats with inherited retinal degeneration: radioautographic and electron microscope evidence for a dual source of extra lamellar material. J Cell Biol 53:185-209.

Leon A, Curtis R (1990) Autosomal dominant rod-cone dysplasia in the Rdy cat: 1. Light and electron microscopic findings. Exp Eye Res 51:361-381.

Lewis TR, Makia MS, Kakakhel M, Al-Ubaidi MR, Arshavsky VY, Naash MI (2020) Photoreceptor disc enclosure occurs in the absence of normal peripherin-2/rds oligomerization. Front Cell Neurosci 14:92.

Loewen CJ, Molday RS (2000) Disulfide-mediated oligomerization of Peripherin/Rds and Rom-1 in photoreceptor disk membranes: implications for photoreceptor outer segment morphogenesis and degeneration. J Biol Chem 275:5370-5378.

Lu Z, Hu X, Reilly J, Jia D, Liu F, Yu S, Liu X, Xie S, Qu Z, Qin Y, Huang Y, Lv Y, Li J, Gao P, Wong F, Shu X, Tang Z, Liu M (2019) Deletion of the transmembrane protein Promlb in zebrafish disrupts outer-segment morphogenesis and causes photoreceptor degeneration. J Biol Chem 294:13953-13963

Mattapallil MJ, Wawrousek EF, Chan CC, Zhao H, Roychoudhury J, Ferguson TA, Caspi RR (2012) The Rd8 mutation of the Crb1 gene is present in vendor lines of C57BL/6N mice and embryonic stem cells, and confounds ocular induced mutant phenotypes. Invest Ophthalmol Vis Sci 53:2921-2927.

Milstein ML, Kimler VA, Ghatak C, Ladokhin AS, Goldberg AF (2017) An inducible amphipathic helix within the intrinsically disordered $\mathrm{C}$ terminus can participate in membrane curvature generation by peripherin-2/ rds. J Biol Chem 292:7850-7865.

Milstein ML, Cavanaugh BL, Roussey NM, Volland S, Williams DS, Goldberg AF (2020) Multistep peripherin-2/rds self-assembly drives membrane curvature for outer segment disk architecture and photoreceptor viability. Proc Natl Acad Sci USA 117:4400-4410.

Moshfeghi DM, Yang Z, Faulkner ND, Karan G, Thirumalaichary S, Pearson E, Zhao Y, Tsai T, Zhang K (2006) Choroidal neovascularization in patients with adult-onset foveomacular dystrophy caused by mutations in the RDS/peripherin gene. Adv Exp Med Biol 572:35-40.

Narfström K, Nilsson SE (1989) Morphological findings during retinal development and maturation in hereditary rod-cone degeneration in Abyssinian cats. Exp Eye Res 49:611-628.

Pittler SJ, Keeler CE, Sidman RL, Baehr W (1993) PCR analysis of DNA from 70-year-old sections of rodless retina demonstrates identity with the mouse rd defect. Proc Natl Acad Sci USA 90:9616-9619.

Rice DS, Huang W, Jones HA, Hansen G, Ye GL, Xu N, Wilson EA, Troughton K, Vaddi K, Newton RC, Zambrowicz BP, Sands AT (2004) Severe retinal degeneration associated with disruption of semaphorin $4 \mathrm{~A}$. Invest Ophthalmol Vis Sci 45:2767-2777.

Salinas RY, Pearring JN, Ding JD, Spencer WJ, Hao Y, Arshavsky VY (2017) Photoreceptor discs form through peripherin-dependent suppression of ciliary ectosome release. J Cell Biol 216:1489-1499.

Schietroma C, Parain K, Estivalet A, Aghaie A, Boutet de Monvel J, Picaud S, Sahel JA, Perron M, El-Amraoui A, Petit C (2017) Usher syndrome type 1-associated cadherins shape the photoreceptor outer segment. J Cell Biol 216:1849-1864.

Sharif AS, Yu D, Loertscher S, Austin R, Nguyen K, Mathur PD, Clark AM, Zou J, Lobanova ES, Arshavsky VY, Yang J (2018) C8ORF37 is required for photoreceptor outer segment disc morphogenesis by maintaining outer segment membrane protein homeostasis. J Neurosci 38:3160-3176.

Spencer WJ, Pearring JN, Salinas RY, Loiselle DR, Skiba NP, Arshavsky VY (2016) Progressive rod-cone degeneration (PRCD) protein requires Nterminal S-acylation and rhodopsin binding for photoreceptor outer 
segment localization and maintaining intracellular stability. Biochemistry 55:5028-5037.

Spencer WJ, Lewis TR, Phan S, Cady MA, Serebrovskaya EO, Schneider NF, Kim KY, Cameron LA, Skiba NP, Ellisman MH, Arshavsky VY (2019) Photoreceptor disc membranes are formed through an Arp2/3-dependent lamellipodium-like mechanism. Proc Natl Acad Sci USA 116:2704327052.

Spencer WJ, Lewis TR, Pearring JN, Arshavsky VY (2020) Photoreceptor discs: built like ectosomes. Trends Cell Biol 30:904-915.

Steinberg RH, Fisher SK, Anderson DH (1980) Disc morphogenesis in vertebrate photoreceptors. J Comp Neurol 190:501-508.

Stenson PD, Mort M, Ball EV, Shaw K, Phillips A, Cooper DN (2014) The Human Gene Mutation Database: building a comprehensive mutation repository for clinical and molecular genetics, diagnostic testing and personalized genomic medicine. Hum Genet 133:1-9.

Stiemke MM, Landers RA, al-Ubaidi MR, Rayborn ME, Hollyfield JG (1994) Photoreceptor outer segment development in Xenopus laevis: influence of the pigment epithelium. Dev Biol 162:169-180.

Stuck MW, Conley SM, Naash MI (2014) The Y141C knockin mutation in RDS leads to complex phenotypes in the mouse. Hum Mol Genet 23:6260-6274.

Stuck MW, Conley SM, Naash MI (2016) PRPH2/RDS and ROM-1: historical context, current views and future considerations. Prog Retin Eye Res 52:47-63.

Tam BM, Moritz OL, Papermaster DS (2004) The C terminus of peripherin/ rds participates in rod outer segment targeting and alignment of disk incisures. Mol Biol Cell 15:2027-2037.

Travis GH, Sutcliffe JG, Bok D (1991) The retinal degeneration slow (rds) gene product is a photoreceptor disc membrane-associated glycoprotein. Neuron 6:61-70.
Tsukamoto Y (1987) The number, depth and elongation of disc incisures in the retinal rod of Rana catesbeiana. Exp Eye Res 45:105-116.

Vaclavik V, Tran HV, Gaillard MC, Schorderet DF, Munier FL (2012) Pattern dystrophy with high intrafamilial variability associated with Y141C mutation in the peripherin/RDS gene and successful treatment of subfoveal CNV related to multifocal pattern type with anti-VEGF (ranibizumab) intravitreal injections. Retina 32:1942-1949.

van Nie R, Iványi D, Démant P (1978) A new H-2-linked mutation, rds, causing retinal degeneration in the mouse. Tissue Antigens 12:106-108.

Volland S, Hughes LC, Kong C, Burgess BL, Linberg KA, Luna G, Zhou ZH, Fisher SK, Williams DS (2015) Three-dimensional organization of nascent rod outer segment disk membranes. Proc Natl Acad Sci USA 112:14870-14875.

White MP, Gorrin GM, Mullen RJ, LaVail MM (1993) Retinal degeneration in the nervous mutant mouse: II. Electron microscopic analysis. J Comp Neurol 333:182-198.

Yang Z, Chen Y, Lillo C, Chien J, Yu Z, Michaelides M, Klein M, Howes KA, Li Y, Kaminoh Y, Chen H, Zhao C, Chen Y, Al-Sheikh YT, Karan G, Corbeil D, Escher P, Kamaya S, Li C, Johnson S, et al. (2008) Mutant prominin 1 found in patients with macular degeneration disrupts photoreceptor disk morphogenesis in mice. J Clin Invest 118:2908-2916.

Yefimova MG, Jeanny JC, Keller N, Sergeant C, Guillonneau X, Beaumont C, Courtois Y (2002) Impaired retinal iron homeostasis associated with defective phagocytosis in Royal College of Surgeons rats. Invest Ophthalmol Vis Sci 43:537-545.

Ying G, Frederick JM, Baehr W (2019) Deletion of both centrin 2 (CETN2) and CETN3 destabilizes the distal connecting cilium of mouse photoreceptors. J Biol Chem 294:3957-3973.

Zulliger R, Conley SM, Mwoyosvi ML, Al-Ubaidi MR, Naash MI (2018) Oligomerization of Prph2 and Rom1 is essential for photoreceptor outer segment formation. Hum Mol Genet 27:3507-3518. 